\title{
Approaching "Baltimore Is Burning" From a Systems Change Perspective: Role of I-O Psychologists as Change Agents
}

Deepshikha (Dia) Chatterjee

Michigan State University

Policing in United States has been under media and public scrutiny for a while now. The focal article "Baltimore Is Burning: Can I-O Psychologists Help Extinguish the Flames?" (Ruggs et al., 2016) is a critical piece of work that not only sheds light on how racial bias may impact police-citizen interactions but also outlines possible ways in which industrial-organizational (I-O) psychologists can intervene to remedy the situation. Although the call to use evidence-based I-O interventions as levers to facilitate a more effective and unbiased police force is timely, it is critical to acknowledge that the charged environment and the controversial nature of this issue imply that some members of the police force might not accept the suggested interventions at face value. Many police officers are upstanding and hard-working individuals and may see the change interventions as an attack. Thus, before attempting to execute any strategies offered in the focal article, I-O psychologists will have to do significant groundwork from a change management perspective: The current crisis needs to be approached from a whole systems change perspective so that we can (a) understand the factors causing the "flames" and define the problem space comprehensively; (b) understand the type of change we need to effect in response to the crisis, stay closely attuned to the system's readiness for change, and also anticipate resistance to change from different levels of the system; and (c) chart a clear outline of what our role should entail as change agents in helping resolve this crisis. Thus, this commentary complements the focal article by juxtaposing authors' recommendations against a whole systems change paradigm, questions their implicit assumptions, and recommends that I-O psychologists act as change agents to help police forces define the problem, find solutions, anticipate resistance, and execute interventions at different levels of the policing system.

\section{Why Should We Take a Whole Systems View of Change?}

We cannot hope to address issues in policing unless we make systemic changes because the current problem afflicts entire communities, spreads

Deepshikha (Dia) Chatterjee, Department of Psychology, Michigan State University.

Correspondence concerning this article should be addressed to Deepshikha (Dia) Chatterjee, Department of Psychology, Michigan State University, 316 Physics Road, East Lansing, MI 48824. E-mail: chatte24@msu.edu 
across state and regional lines, and persists in various police departments. In fact, the crisis is tied to the broader national attitudes, beliefs, and values about what it means to be safe in United States and from whom Americans need to be protected. Police forces and their members are an open system that not only learns from and reacts to the environments in which it is embedded but also influences the broader environment (French \& Bell, 1995, p. 89). Thus, the authors are correct in asserting that the crisis can only be solved by "truly systemic and systematic interventions that examine and address psychological processes at the individual, organizational, and societal levels" (Ruggs et al., p. 543). However, the recommendations have been offered with little to no discussion about how the systems view may be applied to the crisis and what specific issues should be considered given the whole systems change paradigm. Although the focal article outlines several ways in which I-O psychologists can help remedy the current crisis, it only briefly acknowledges that the strategies offered are in fact change interventions (Schein, 2003). In addition, although the authors state that the crisis is a "systemic" problem, they do not discuss how I-O psychologists might precipitate, effect, and sustain successful, large-scale, system-wide change effort (Ruggs et al., p. 543). Therefore, this commentary explores how the whole systems change perspective might align with the recommendations offered. The goal is to spur questions and conversations that can help both practitioners and researchers better understand the systemic impact of change interventions in the policing system.

Taking a whole systems change view of the problem can help us carefully consider the current crisis from various perspectives and avoid the pitfalls of diving into a problem solving mindset (Checkland, 2000). For example, systems view forces us to acknowledge that the subparts of the policing system and its environment are interrelated. Thus, it is critical for us to (a) identify the various stakeholders involved, (b) understand the constraints and boundaries of the policing system, (c) know the various system layers and niches that impact how policing itself unfolds, and (d) understand the norms, resources, regulations, and operations that underlie the policing system from a bottom-up perspective, so we can have a rich understanding of the context before attempting to outline any solutions (Foster-Fishman, Nowell, \& Yang, 2007). This view also illuminates the fact that, although the authors recommend several potential levers to remedy the crisis, they do not expound on how and when to engage different levers. For example, although the authors propose both transformational change levers such as leadership and organizational climate and transactional change levers such as performance management, training, and personnel selection (French \& Bell, 1995), they do so without any discussion on how these might differentially impact various interrelated parts of the system, such as squads, leader- 
member dyads, police departments, or the environmental components such as the communities, courts, and/or state officials. Furthermore, once these systems are changed in line with the authors' recommendations, there is no discussion of how the interrelationships of the subsystems might change and therefore impact the overall policing system.

A whole systems view of change also cautions against an overreliance on changing the visible elements of the policing system such as performance management, selection procedures, training, and so forth. Although these are useful, they tend to create incremental forms of change (French \& Bell, 1995). In contrast, changing the deep structures that guide the policing system is more likely to produce transformational forms of change (FosterFishman et al., 2007; French \& Bell, 1995). To effect lasting changes in policing system, I-O psychologists will have to also study the deep structures that are "normative elements such as attitudes, values, beliefs, expectations, and tacit assumptions that drive behaviors of its members" (Foster-Fishman et al., 2007, p. 205) in addition to focusing on the visible structures that produce incremental changes. Although authors bring the racial bias lens to the table as an explanation for some of these deep structures, it is vital to note that (a) some deep structures might remain hidden unless we study the policing system with the intention of learning more about it, and (b) although the racial bias view may very well explain the problem, it needs to be acknowledged that this is but one view of the problem.

Finally, although we know that systems rely on and are sensitive to feedback for their survival (French \& Bell, 1995), many feel that despite negative feedback, policing has not changed much. It is important to consider when and why police departments might or might not embrace feedback. Is it perhaps the case that the racial bias perspective of the current crisis runs counter to their deep structures or organizational schemas? Might they truly think this view to be so egregiously wrong that police officers and leaders are coding the feedback as inaccurate and unrepresentative? If that is the case, then pushing value inconsistent changes will be an uphill battle and cause the change interventions recommended in the article to be actively resisted or, worse, completely rejected (Foster-Fishman et al., 2007). Or might it be the case that police forces as systems are in a state of "dynamic homeostasis"that is, they are seeking to maintain the organizational equilibrium against all odds? If so, the system might be set up in such a way that adapting to the environmental feedback is seen as disruptive to the way work gets done. If this is indeed the case, then proposing strategies such as diversity and sensitivity training, personnel selection, or performance management is likely to be perceived as inadequate and disruptive and likely to be labeled as ineffective even before the strategies are ever implemented (Foster-Fishman et al., 2007). 


\section{What Type of Change Is Needed and What Issues Need To Be Considered?}

In making their recommendations, the authors make several implicit assumptions about the type of change, the role of change agents, and also the recipients of change. First, the recommendations seem to be driven by the implicit assumption that the police forces and the communities as a system are ready to accept these "incremental modifications" because the change interventions "make sense within the established framework or method of operating" (Bartunek \& Moch, 1987, p. 484). This view of change is consistent with the first order change or incremental change. However, when the authors detail their strategies they seem to align with the second order change perspective-that is, the strategies aim to fundamentally reframe how things are currently done in the system (Bartunek \& Moch, 1987). For example, strategies such as building positive organizational climate are aimed at helping the police usher a more positive organizational schema of race and ethnicity and unfreeze the old behaviors and values that might be rooted in racial bias (Bartunek \& Moch, 1987). This misalignment is cause for concern because understanding what type of change we want to effect is critical to a successful change effort. Although both incremental and transformative changes can and should be used in dealing with more complex systemwide change efforts (cf. Van de Ven \& Sun, 2011), it is pertinent for change agents to have a clear sense of when and why different frameworks should be used.

The focal article's approach assumes a prescriptive, top-down, externally induced and regulated notion of change-or the life cycle process theory view (cf. Van de Ven \& Sun, 2011). Although prescriptive change approach is certainly needed and can be valuable, change in complex systems also calls for third order change efforts. Third order change efforts attempt to "help organization members develop the capacity to identify and change their own schemata as they see fit" (Bartunek \& Moch, 1987, p. 487). This is a necessary step because under experts' guidance it can spark important conversations in the policing system about the issues outlined in the focal article. For example, conflicts and opposing interests in the various policing subsystems can be turned into critical change levers by using a dialectic change paradigm that focuses on generating solutions by conflict resolution (Austin, 2009; Van de Ven \& Sun, 2011). Insights gleaned from these conversations can then be leveraged into solutions that will have been generated bottom up and will reflect the perspectives of multiple stakeholders across the policing system. When people participate in problem solving, it increases buy in and co-ownership of solutions (Bartunek, Rousseau, Rudolph, \& DePalma, 2006; Irvin \& Stansbury, 2004). However, it is important to note that this approach requires a different philosophy to change than discussed so far. Although both first order and second order change interventions rely on change agents 
to prescribe answers to problems, the third order change interventions call for change agents to help members of the system define the problems by engaging in reflection, facilitating search for solutions, and guiding sensemaking of the change process itself (Bartunek \& Moch, 1987; Van de Ven \& Sun, 2011).

Finally, authors assume that the policing system is ready to change as is exemplified by their lack of discussion on what happens if the police leadership cannot effect the strategic changes proposed. We cannot assume readiness for change just because there is widespread negativity among members of public about how communities are policed in United States. In fact, the policing system is known for its deeply held value of banding together in times of external threats, and this value can make police officers close ranks in response to change efforts ("blue wall of silence"; Chin \& Wells, 1998). Thus, we cannot assume that change agents will not encounter resistance to change. As discussed earlier, it is important to remember that commanding incremental changes in systems does not automatically stave off a system's natural tendency for homeostasis (Senge, 2006). Given the organizational, social, cultural, and political expectations of the police leadership, the policing system and various power groups embedded in it are more likely than not to maintain "tacit support to the status quo" (Austin, 2009; Bartunek \& Moch, 1987, p. 487). Austin (2009) asserts that oftentimes leaders derive their power from the status quo-if racial bias is the basis of the current crisis then it likely serves critical functions in the policing system that we might be unaware of. Perhaps racial bias serves to further power structures in a hierarchical and politicized environment and/or is used to define "good police work." If this is the case, then even though the recommendations might seem like incremental changes, they are likely to be perceived as radical changes. Given the complexity of the policing system, likely lack of readiness for change, and the fact that members and leaders in the system might see the proposed changes as controversial and an affront to their professional identity, I-O psychologists will have to prepare for change interventions to (a) not unfold in a linear and anticipated direction, (b) impact distal and proximal parts of the system in intended and/or unintended ways, and (c) create strong affective reactions among change recipients (Cunningham et al., 2002; Huy, 2001; Rafferty \& Restubog, 2010).

To sum, change is often messy (Van de Ven \& Poole, 1995), but through it all, I-O psychologists must not lose sight of the fact that while the current crisis disproportionately hurts the members of the public, the upstanding members of the police force may also carry the weight of this burden on their professional identities. How might their professional experiences be shaped by the crisis? Do the upstanding members of the police feel the loss of public goodwill and trust as it relates to their feelings of both actual and/or 
perceived decrements in safety in dealing with communities? What impact does this have on how they police? Thus, any resolution of the crisis will call for I-O psychologists to be closely attuned to the readiness for change in the systems they wish to impact and to also anticipate resistance to change at different levels of the system.

\section{What Is the Role of I-O Psychologists Given the Whole Systems Change Paradigm?}

The authors also seem to assume that I-O psychologists not only can use their expertise to accurately outline the problems in the policing system but also can propose correct solutions, which if implemented, can help the police force function more effectively. Although I agree with (a) their approach of targeting multiple solutions at different levels of the system because the current crisis is a complex problem that requires various organizational levers to be exercised and (b) their astute choice of using both transactional and transformational levers (French \& Bell, 1995) to ensure that the crisis can be attacked with different levels of precision, I posit that we also need to align the change agents' role with the type of change effort under consideration. I-O psychologists can certainly function as experts to diagnose the problems inherent in the policing system and advocate solutions when using a first order view of change, but this approach is problematic for the transformative change efforts that are also needed to resolve the current crisis (Bartunek \& Moch, 1987). The reason this is problematic is not because I-O psychologists do not have the expertise; it is problematic because it relies on the assumption that as experts we have the dominion over correct mental models to solve the crisis, when in fact, we are external to the system and know very little about it (Foster-Fishman et al., 2007; Schein, 2003).

We know that changes at a whole systems level call for first creating a comprehensive and "systemic awareness of the problem situation" (FosterFishman et al., 2007, p. 199). Thus, transformational change efforts necessitate that the change agents bring as many different stakeholders to the discussion table at the problem definition stage as possible (Checkland, 2000; Foster-Fishman et al., 2007). This is vital because the manner in which we frame the problem directs the depth and scope of the solutions. In line with this, it is thus also important for I-O psychologists as change agents to understand our own biases in proposing solutions. Although our training might point to racial biases as the root cause of the crisis, it is but one view of the problem and by no means represents an exhaustive understanding of precipitating factors in the policing context. For example, I agree with the authors that "the lack of demographic diversity within police forces, especially as it misaligns with the demographic diversity profile of the community" may be implicated in fueling tensions between police and community 
members (Ruggs et al., p. 533). I also agree with the authors that perhaps recruiting strategies need to be designed to bridge this gap. But before we jump to problem solving, we need to ask broader questions such as why might police not recruit diverse candidates to begin with? What factors in their system might propel these decisions? Racial bias may very well be one important factor, but unless we examine the system closely, we might miss other critical factors, thereby only offering partial solutions. Partial solutions have been associated with failures of change efforts (Foster-Fishman, Nowell, \& Yang, 2007). In short, limiting ourselves to an action strategy approach that focuses on "diagnosing and correcting breakdowns" without concurrently engaging in reflection strategy can impede effective and lasting systems change (cf. Van de Ven \& Sun, p. 59).

As external subject matter experts to the policing system, we cannot effect whole scale change because we do not understand the system's organization, its history, or its inherent complexity. We are therefore ill equipped to define the problems that have created the conditions for the current crisis (Foster-Fishman et al., 2007). However, I-O psychologists can act as change agents and bring diverse stakeholders such as police officers from various levels of the hierarchy, community members, neighborhood watch associations, city and state officials, social workers, and so forth to the table and guide them to define the problem. The problem definition process might look different across different communities, regions, and states, but this is to be expected. The goal should be to get an exhaustive understanding of how various stakeholders view the problem and only then guide them in creating their own solutions. This is not to say that we should not use the approaches used in the focal article, but the prescriptive recommendations will have to be tailored for each policing system. Contextualizing the recommendations by facilitating dialogue about them across the policing system is critical so the solutions can be truly owned by the relevant stakeholders and the positive change efforts can be sustained once the change agents leave.

\section{Conclusion}

So far, this commentary has called for grounding the recommendations offered in the focal article in a whole systems change perspective. Although I-O psychology can offer many evidence-based solutions to help "extinguish the flames," we are likely to get better results if our interventions are appropriately targeted at different levels of the policing system. The commentary also calls for aligning the role of I-O psychologists as change agents to the different types of change efforts needed in solving the current crisis. It is hoped that the whole systems change approach to the crisis will help bridge the frayed relationships between police forces and communities they serve 


\section{by including diverse voices in creating a comprehensive problem definition and finding solutions that are more likely to be sustained in the policing system.}

\section{References}

Austin, J. R. (2009). Initiating controversial strategic change in organizations. OD Practitioner, 41(3), $24-28$.

Bartunek, J., \& Moch, M. (1987). First, second, and third order change and organizational development interventions: A cognitive approach. Journal of Applied Behavioral Science, 23, 483500 .

Bartunek, J., Rousseau, D. M., Rudolph, J. W., \& DePalma, J. A. (2006). On the receiving end: Sensemaking, emotion, and assessments of an organizational change initiated by others. The Journal of Applied Behavioral Science, 42(2), 182-206.

Checkland, P. (2000). Soft systems methodology: A thirty year retrospective. Systems Research and Behavioral Science, 17, S11-S58.

Chin, G., \& Wells, S. (1998). Blue wall of silence as evidence of bias and motive to lie: New approach to police perjury. The University of Pittsburgh Law Review, 59(2), 233-300.

Cunningham, C. E., Woodward, C. A., Shannon, H. S., Macintosh, J., Lendrum, B., Rosenbloom, D., \& Brown, J. (2002). Readiness for organizational change: A longitudinal study of workplace, psychological and behavioural correlates. Journal of Occupational and Organizational Psychology, 75(4), 377-392.

Foster-Fishman, P. G., Nowell, B., \& Yang, H. (2007). Putting the system back into systems change: A framework for understanding and changing organizational and community systems. American Journal of Community Psychology, 39(3-4), 197-215.

French, W., \& Bell, C. (1995). Organizational development: Behavioral science interventions for organization improvement (5th ed.). Englewood Cliffs, NJ: Prentice Hall International.

Huy, Q. N. (2001). Time, temporal capability, and planned change. Academy of Management Review, 26(4), 601-623.

Irvin, R. A., \& Stansbury, J. (2004). Citizen participation in decision making: Is it worth the effort? Public Administration Review, 64(1), 55-65.

Rafferty, A. E., \& Restubog, S. L. (2010). The impact of change process and context on change reactions and turnover during a merger. Journal of Management, 36(5), 1309-1338.

Ruggs, E. N., Hebl, M. R., Rabelo, V. C., Weaver, K. B., Kovacs, J., \& Kemp, A. S. (2016). Baltimore is burning: Can I-O psychologists help extinguish the flames? Industrial and Organizational Psychology: Perspectives on Science and Practice, 9(3), 525-547.

Schein, E. H. (2003). Five traps for consulting psychologists: Or, how I learned to take culture seriously. Consulting Psychology Journal: Practice and Research, 55(2), 75-83.

Senge, P. M. (2006). The fifth discipline: The art and practice of the learning organization. New York, NY: Currency/Doubleday.

Van de Ven, A. H., \& Poole, M. S. (1995). Explaining development and change in organizations. Academy of Management Review, 20(3), 510-540.

Van de Ven, A. H., \& Sun, K. (2011). Breakdowns in implementing models of organizational change. Academy of Management Perspectives, 25(3), 58-74. 